\title{
The Constructive Marginal of Moby-Dick: Ishmael and the Developmental Model of Intercultural Sensitivity
}

\section{Jeff Morgan \\ Lynn University}

Those who attach a high importance to their own opinion should stay at home Aldous Huxley, New York Times interview, Sept. 7, 1926

Cultural sensitivity theory is the study of how individuals relate to cultural difference. Using literature to help students prepare for study abroad, instructors could analyze character and trace behavior through a model of cultural sensitivity. Milton J. Bennett has developed such an instrument, The Developmental Model of Intercultural Sensitivity (DMIS), which measures behavior from ethnocentric to ethnorelative. Cultural sensitivity research has proven time and again that Bennett's DMIS is a strong model after over thirty years. In a 2003 article in The International Journal of Intercultural Relations, R. Michael Paige and others analyze a new model, co-created by Bennett, called the Intercultural Development Inventory (IDI). It is based on Bennett's old model. The IDI suggests different stages of development but is so similar to the DMIS that the research shows the strength of Bennett's DMIS, which I will use with Herman Melville's Moby-Dick to chart Ishmael's cultural sensitivity.

The simplicity of the DMIS may very well help attest for its longevity in the field. The DMIS can be seen as a chart, beginning with ethnocentric behavior. Ethnocentrism moves through three stages, starting with denial, in which the individual appears to even deny the existence of one who is culturally different. Next is the defensive stage. Here, the individual will characteristically denigrate those culturally different than himself. In the final stage of ethnocentrism, minimization, the individual, when gauging one culturally different than himself, will only embrace those characteristics that he also has. The next three stages encompass the ethnorelative phases of cultural sensitivity and are initially marked by the individual's acceptance of difference, followed by his adaptation of certain cultural aspects not native to himself. The last stage is integration, which can be taken ad infinitum, producing a constructive marginal, one who has such a diverse ethnic makeup that he only fits in withother constructive marginals. In 1993, Janet M. Bennett noted Barack Obama, the first black elected president of the Harvard Law Review, 
as the epitome of constructive marginalism. "In some ways, Obama presents us with an ideal case study of a man in the middle of many cultures. While various cultural groups may each seek his allegiance, he appears to claim for himself an identity that is beyond any single cultural perspective" (Bennett 110). This process also describes Ishmael, the weary, wayworn wanderer who constructs his own identity in Herman Melville's American classic, Moby-Dick.

The second decade of the new millennium marks a time of great change and, consequently, great challenges. In the United States, one significant change involves immigration and the growing populations of a number of ethnicities. In a 1997 commencement speech at the University of California at San Diego, Bill Clinton spoke of the inevitability of no cultural majority existing in this country by 2050. "A half-century from now, when your own grandchildren are in college, there will be no majority race in America" (A4). More recent statistics from the U.S. Census Bureau seem to bear this out, this goes to show how so much will depend upon cultural sensitivity. Often reserved for students who are on the verge of studying aboard, cultural sensitivity theory can help so many more work toward cultural sensitivity. For those students who cannot study abroad, they can travel in their minds with the likes of Ishmael and learn from his experiences how to deal with cultural difference, and for those who can, reading Melville's Moby-Dick with Bennett's DMIS in mind can allow for analysis that leads to true insights into how one ought to interact when experiencing cultural difference. Furthermore, in a world grown increasingly smaller, one gets to practice ethnorelativism in his own backyard, and reading about Ishmael, Melville's constructive marginal, through the gaze of cultural sensitivity theory can ultimately help us live our lives in our very neighborhoods.

\section{The Historical Critical Context of Ishmael and Cultural Sensitivity}

Others have analyzed the character of Ishmael within a context of cultural sensitivity. Melville clearly aligns Ishmael with Jonah, inviting criticism based on the allusion. In his landmark American Renaissance: Art and Expression in the Age of Emerson and Whitman (1941), F. O. Matthiessen discusses the runaway nature of Ishmael's character. He characterizes Ishmael as, at least early on in the novel, an existentialist in the sense, particularly, of "an individual's separation from his fellow human beings" (443). For Matthiessen, Ishmael's cultural sensitivity conflict, his isolation, climaxes still early in the novel with Queequeg. "When Ishmael recognized that 'the man's a human being just as I am,' he was freed from the burden of his isolation, his heart was no longer turned against society" (Matthiessen 443). Analyzing Matthiessen's reading 
of the conflict and climax within a framework of cultural sensitivity reveals the basic truths of Bennett's cultural sensitivity model as Ishmael moves from ethnocentric to ethnorelative behavior, primarily because he shared a bed with a presumed savage, a strong representation of integration, the final phase in Bennett's model.

However, by the end of the novel Ishmael becomes a constructive marginal, and, still, this is an area Matthiessen explores. He addresses Ishmael's multiple perspectives in Melville's chapter 42 "The Whiteness of the Whale." Ishmael's willingness to accept multiple interpretations of the symbolism of the color white follows two chapters in which Melville suggests the need for cultural sensitivity. In chapter 40, Melville gives a good idea of how multi-cultural the Pequod is; not all the crew equally appreciates the singing and dancing, and there is almost a battle royale at the end. These individuals clearly need to be more accepting of difference, but the next chapter characterizes Ishmael as one who can read a symbol and abide by its hidden truth, namely here, the dark portents. Here, he is not unlike Hamlet, who has given himself to providence. Ishmael abides by the majority opinion, confessing "I gave myself up to the abandonment of the time and the place; but while yet all a-rush to encounter the whale, could see naught in that brute but the deadliest ill" (203). An activist would have Ishmael intervene, but Ishmael is not an activist; he is a constructive marginal, constantly creating his own reality (M. Bennett 64), a reality that Janet Bennett characterizes as "commitment in relativism" (117) and which Matthiessen pegs decades before when he recognizes that "one thing that could redeem 'the wolfish world,' the Ishmael of Moby-Dick found, was sympathy with another human being" (443).

Other great scholars after Matthiessen also characterize Ishmael in terms of cultural sensitivity but without the context of cultural sensitivity theory woven into their analyses; however, it is there in spirit. It is there when Richard Chase in his significant book from 1957, The American Novel and Its Tradition, writes about Ishmael looking into the water. Unlike Ahab, Ishmael, as Chase points out, see his "own image in a context of life and reality" (108). In terms of cultural sensitivity theory, Chase's contrast is clear, for Ahab is the exemplar for ethnocentric behavior, his condition, in fact, frequently referred to as monomaniacal. Ishmael, on the other hand, views himself in a context. Leslie Fiedler, three years later in his Love and Death in the American Novel, further underlines the importance of understanding Ishmael from a standpoint of cultural sensitivity. Fiedler focuses on Ishmael's relationship with Queequeg and is quick to draw attention to Ishmael's cultural insensitivity early in the novel. "Everything about Queequeg appalls him," but in a short time, "he awakens in the harpooner's embrace" (534). Queequeg's tomahawk 
pipe becomes a peace pipe, and Queequeg's idol, Yojo, becomes the recipient of repeated ritualistic condescension from Ishmael. Fiedler marks Ishmael's relapses, as with Elijah after Ishmael and Queequeg sign on with the Pequod, or when Ishmael "lent his voice to the pledge of the maddened crew to pursue the abominable quest" (550). Ultimately, Fiedler, too, recognizes Ishmael's ethnorelativism, turning to "The Monkey Rope" chapter of the novel to help symbolize integration and the "A Squeeze of the Hand" chapter to epitomize integration with Ishmael asserting, "nay, let us all squeeze ourselves into each other; let us squeeze ourselves universally into the very milk and sperm of kindness" (456).

Since these pioneering works on American Literature, a plethora of books have added to the analysis of Ishmael as a constructive marginal whose character goes through the process of cultural sensitivity. The same year Criterion brought out Fiedler's fresh views of Ishmael and Queequeg's relationship, Merlin Brown's The Long Encounter: Self and Experience in the Writings of Herman Melville came out. Brown, though, writes "we must not expect an exact sequence of steps" charting Ishmael's growth of cultural sensitivity (241). With Bennett's DMIS, now we can. In 1973, Robert Zoellner continued looking for a process, a model, within which the growth of Ishmael's character could be better explained, and he notes Ishmael's view of the whale moves from demonic monster to fish to mammal to brother (185). In his 1991 book, The Machine in the Garden, Leo Marx asserts how Ishmael, after surviving the adventure of the Pequod, develops a narrative voice that embraces two distinct voices, "the claims of our collective, institutional life and the claims of nature" (285). In the 80s and 90s, writers such as Robert Martin and William V. Spanos, in other large works on Melville, analyze Ishmael in economic terms addressing two sides to Ishmael's character, the individual that leads to imperialism and the more constructive marginal type of characterization that leads to a more liberating multiplicity and suggests anti-capitalistic themes. To be sure, Nina Baym, John Bryant, and Lawrence Buell all address "Melville's complex marginalizing rhetoric" (Bryant 708).

In the past half century, several articles have appeared addressing the issue of Ishmael's character and constructive marginalism. In 1967, David Hirsch writes briefly in $A N \& Q$, "Ishmael actually presents himself in two guises in the novel" (115). Melville, though, does not stop the multiple layers of Ishmael's constructive marginal characterization at two. Three fine essays on the subject of multiplicity come out in the 1980s. Philip Egan's "Time and Ishmael's Character in 'The Town-Ho's Story' of Moby-Dick” focuses on the story within the story to assert Ishmael's discomfort with his audience and pinpoint his growth toward constructive marginalism at some mid-point; 
however, Egan writes that "we cannot refer to Moby-Dick as a bildungsroman or 'novel of education' because we do not really know the stages and methods by which Ishmael achieves his growth" (338). This, again, is where Milton Bennett's DMIS can help. Mark Patterson, in a 1984 writing, anticipates Ishmael's remarkable growth and analyzes a process but doesn't go all the way with Ishmael, relegating his development in a tone of loss when he writes that Ishmael's "voice later seems to disappear into the narrative itself, mimicking a variety of other voices as the novel progresses" (297). The disappearance he refers to is actually Ishmael's new character, a kind of rainbow coalition of cultural influences. In 1989, Susan Lyne Knutson clearly brings the discussion into the context of cultural sensitivity studies when she analyzes "Wheelbarrow," chapter 13 in the novel, in which Queequeg turns cultural tables on Ishmael, pointing out the difficulties one has grasping customs when in a different culture and how the natives are inclined to be derisive. Knutson claims the passage "indicates that Melville was aware of the problems with ethnocentric vision, and was perhaps as conscious of them as a man of his time might be" (par. 27).

More recently, the critical analysis seems to want to follow Bennett's stages. Robert Martin returns to the subject in a smart 1990 essay, "Sleeping with a Savage: Deculturation in Moby-Dick," in which he asserts Ishmael's ethnocentric character early in the novel is the result of cultural homophobic conditioning. He recognizes that Melville clearly juxtaposes Queequeg's Yojo with Father Mapple's Christ to illustrate the existence of different visions, and recognizes different voices in Ishmael, noting, at least three. Joseph Adriano's "Brother to Dragons: Race and Evolution in Moby-Dick," from 1996, points to Melville's thematic tendency to undercut traditional hierarchies, which echoes the work of cultural sensitivity scholars who point to the traveller abroad who now prefers abroad to the United States. Adriano takes Ishmael's character even farther down the line of Bennett's cultural sensitivity development, characterizing Ishmael as too smart to fight the Leviathan; instead, he embraces it, just as he embraces the harpooners who also embrace the Leviathan. This is the community of constructive marginalism. Recent ecocriticism, a field closely related to cultural sensitivity, by Elizabeth Schultz and Susan Kalter expands that community to include the whale. Schultz focuses on "cetacean and human kinship" (104) that recalls Bennett's stage of minimization in the way that Ishmael admires the human qualities in the whale. Kalter writes of savagism, which closely resembles Bennett's ethnocentrism. "Melville's radical ecology," to Kalter, connects "to the valuing of Native American cultures" (13). Still furthering the community, Thomas L. Dumm, in a 2005 essay, expands it to include the reader. Dumm characterizes readers of the novel as fellow 
constructive marginals, and Ishmael asking to be named at the beginning of the novel can be seen as an effort toward a union of isolatoes or fellow constructive marginals (400). Bringing the reader into the discussion as he does suggests how cultural sensitivity classes using literature can have some benefit.

\section{Understanding Ishmael using the DMIS}

Let us now turn to the text for a close reading and analyze this process of Ishmael's growth toward becoming a constructive marginal, and there is no better place to start than the beginning. We have already seen how Robert Martin suggests cultural conditioning that has gone into Ishmael's character even before the curtain rises on Moby-Dick. Before the action starts at the Spouter Inn, Melville tells us a lot about Ishmael. He can tell a story, which is no small feat; however, despite this skill, Ishmael is poor, disinterested with society, grim, of a damp and drizzly soul, fixated on death, and ready for violence. He also needs to get to water to best reflect. Ishmael minimalizes cultural difference when he lumps everyone with himself as "tied . . . nailed ... [and] clinched" (4), and he exhibits similar ethnocentric behavior when he heralds the universal appeal of water for purposes of reflection. Further minimization occurs when Ishmael places everyone on the stage, the play being the thing that providentially unites us. Early in the novel, Ishmael trivializes difference, exhibiting what Milton Bennett would characterize as transcendent universalism since Ishmael seems to have fallen for the single truth fallacy (4144).

Once Melville takes the action to the Spouter Inn, which represents worldliness due to its diverse clientele, Ishmael's ethnocentrism takes center stage. A conflict arises because Ishmael must share a bed with another man, Queequeg, but Ishmael has not seen the harpooner. Our hero claims, "I would put up with the half of any decent man's blanket" (15). The key word there is the adjective decent. Ishmael begins "to feel suspicious of this 'dark complexioned harpooner" whose bed he is to share. He even associates the harpooner with the devil and assumes a position of superiority over the man he is supposed to sleep with, thinking the harpooner "must undress and get into bed" (16) first. Ishmael would clearly be more comfortable sleeping with a man more like himself, like Bulkington, aloof, alone. Ishmael's anxiety with strangeness is classic defense behavior in cultural sensitivity theory. He is experiencing a cultural conflict (Wurzel 6-7), and it is a great conflict because the harpooner is so different than Ishmael. As Paige points out, the greater the cultural difference, the greater the challenge ("On the Nature" 5).

Ishmael appears to have skipped Bennett's first stage of cultural sensitivity, denial. Bennett characterizes the first phase of this ethnocentric behavior as 
isolation, a trait seemingly not part of Ishmael's character. A teacher who chooses to get away from it all by boarding a whaler that symbolically represents the world, Ishmael is aware of cultural difference. Boarding the Pequod symbolically suggests Ishmael is actually embracing the world. Ishmael does, though, get a little defensive about cultural difference, as we have seen above. Ishmael exhibits the three main characteristics about defense. He denigrates the harpooner when associating him with the devil. He also shows his sense of superiority over the harpooner with his condescending tone when describing Queequeg's ritual with his idol. Not long after the episode at The Spouter Inn, Ishmael even begins Bennett's final phase of defense, reversal, in which the ethnocentric person denies his previous superiority and acknowledges his own inferiority. Though Ishmael seems to skip the stage of denial, he definitely exhibits behavior characteristic of Bennett's second stage, defense. Ishmael will proceed through the other stages of Bennett's Developmental Model of Intercultural Sensitivity, and he will experience relapses along the way; however, within The Spouter Inn episode, Melville packs a boatload of details that lend themselves to looking at his novel through the lens of cultural sensitivity theory.

A brief look at some other key action under the roof of the Spouter Inn reveals how significant the episode is in establishing Ishmael's course through the stages of cultural sensitivity, starting with defense. He does accept to share a bed with Queequeg, but only after it appears Queequeg isn't returning to the inn. He tries on Queequeg's poncho-mat, but, seeing his reflection, becomes alarmed and disrobes. Certain that his roommate is an evil killer, Ishmael commends himself "to care of heaven" (22). Once Ishmael finally sees Queequeg's face, he revolts. Ishmael seems to want to accept Queequeg, but his fears result in him virtually denying Queequeg's existence by remaining silent and pretending not to be there. Once the two are aware of the other's existence, an apparent murder ends with Ishmael admiring Queequeg's simple integrity, which suggests Bennett's idea of reversal, but he minimizes Queequeg when he says, "the man's a human being just as I am" (26). This is very limited acceptance and primarily indicative of Bennett's ethnocentric characterization. After all, as the episode comes to a close, Ishmael demands that Queequeg adapt to Ishmael's ways, and Queequeg does so willingly. Still, at the very end of the episode, and suggestive that Ishmael will progress through further stages of cultural sensitivity, we have the positive sign of Ishmael sleeping his best sleep ever.

Life with Queequeg after that first night at the Spouter Inn continues to conflict Ishmael as he struggles with his own ethnocentric side. Melville's symbols, such as their embrace, the patchwork quilt, Queequeg's tattoos, 
and the blending of the latter two, represent cultural integration, but soon give way to more ethnocentric detailing. For example, Ishmael starts to see Queequeg as superior in a bit of reversal, but soon reverts back to a standard culturally defensive posture. He adopts a defensive tone during "The Street," chapter six, associating Queequeg with diction such as "outlandish" and "wild" and "cannibals" and "savages" (36). Melville also mixes in more ethnorelative detailing as Ishmael accepts Queequeg's harpoon as a razor and an eating utensil. There is a lot that Ishmael can learn about cultural sensitivity from Queequeg, especially from the way the harpooner adapts to boots, but an even stronger teaching moment occurs when Ishmael sees Queequeg at the Whaleman's Chapel. After the Spouter Inn episode, Ishmael is on his way toward becoming a constructive marginal, but Queequeg seems to be already there.

At the Whaleman's Chapel, Melville provides significant detailing that needs to be viewed with a culturally sensitive gaze. For years, sailors from around the world have found themselves in New Bedford and the Whaleman's Chapel, each needing to adapt to certain things in these settings, so Ishmael's visit to the house of worship definitely suggests he's integrating. Particularly, Father Mapple's sermon is instructive. Stylistically, the sermon is important in terms of cultural sensitivity because it is the first extended speech from someone other than Ishmael and subsequently advances Melville's theme involving multiplicity and ambiguity. Furthermore, the actual content of Father Mapple's sermon also advances cultural sensitivity. The preacher asks his parishioners to sacrifice what they want to do in order to follow another, in this case, God. This is not unlike Queequeg's sacrifice with the boots.

After church, the chapters leading up to the disembarking of the Pequod further Ishmael's education, albeit in a rather wavering way. Ishmael reverts to a defensive tone with diction such as "heathenish," "savage," and "hideously marred" (55), referring to Queequeg's tattoos. But, he adds, "Through all his unearthly tatooings, I thought I saw the traces of a simple honest heart" (55). This acceptance, which is Bennett's fourth stage and first of three in the ethnorelative stages, continues for a page in the novel until a minimization setback occurs with some reversal, both indicative of Ishmael backsliding to ethnocentric stages. Ishmael minimizes Queequeg by suggesting that one thing he likes about the harpooner is his phrenological resemblance to George Washington, a comparison that also reveals Ishmael's admiration for Queequeg. More of the same can be seen a bit later when Ishmael sees the wisdom in adopting some of Queequeg's way of looking at the world, mainly indifferent that is, and in spending a second night together. Along the way, they share a pipe, symbolic of their integration, which Queequeg takes a step 
farther with more physical connection that represents a bosom friendship and even marriage. At the same time Ishmael behaves in a more ethnocentric way with lines such as "I'll try a pagan friend thought I, since Christian kindness has proved but hollow courtesy" (57), clearly exemplifying Bennett's reversal description. This jagged process leading to Ishmael's constructive marginality is not unprecedented in cultural sensitivity theory. In fact, Kenneth Cushner describes a tension in someone who is attracted to cultural maintenance and to cultural pluralism (353). In Ishmael's case, when Ishmael refers to Queequeg as a pagan, he would be in the maintenance side of the conflict, and the more open side is evident in the openness to spend a second night with Queequeg. A formal analysis of Ishmael's conflict here clearly can be articulated using cultural sensitivity theory, which is why students could benefit from mapping Ishmael's sojourn of the self.

After a few pages dripping with ethnocentrism, Melville again brings up Ishmael's conflict as described by Cushner. Ishmael's biography of Queequeg is especially telling here. The diction mixes words such as "savage" and "wild" and all of their connotative baggage with a more regal tone. This is soon followed by the aforementioned wheelbarrow scene, significant for its lesson that is perhaps best described in Queequeg's words: "It's a mutual, joint-stock world, in all meridians" (68), which alludes to him helping the greenhorn and the captain, who both thought lightly of Queequeg. To be sure, the harpooner serves as a strong role model for Ishmael. Queequeg is eager to integrate, hoping to adapt certain characteristics that he can then take home for his people. However, as Melville's narrative is about set to sail, Ishmael still reveals himself as culturally conflicted, unable, for instance, to understand Queequeg's spirituality even though he certainly tries.

The trying shows Ishmael struggling through Bennett's stages, and in the chapters before embarkation, Ishmael reveals himself to still have one foot stepping back into ethnocentrism and the other stepping forward into ethnorelativism. For example, Ishmael combines acceptance with defense when he says at the start of chapter 17, "I cherish the greatest respect towards everybody's religious obligations, never mind how comical" (90). The two sides to that quote help show Ishmael has a way to go. In fact, most of Melville's detailing keeps his characterization of Ishmael within ethnocentric parameters. Unlike Ahab, whom Melville starts characterizing in chapter 16, Ishmael has not had the education and experience to make him a constructive marginal. Still, despite all of Ishmael's ethnocentric behavior, referring to Queequeg's Ramadan rituals as intolerable, despite his differences with Queequeg, they saunter off together to the Pequod. It is there where Ishmael will continue to grow, referring to life aboard the Pequod as his Yale and Harvard. 
The whole novel takes a turn once the Pequod is off, and cultural sensitivity seems to take a back seat to other more pressing thematic concerns in Melville's story. Ishmael, indeed, appears to disappear. Yet, the whole novel can be seen as maintaining a thematic focus on cultural sensitivity. Even chapters that focus on other mammals, such as the chapter on cetology, work, as Marx, Schultz, Kalter, and others have pointed out, within a context of cultural sensitivity theory because Melville, here, forces the reader to change his view of the whale, just as he forces the reader to change with further characterization of Ahab. The infamous captain of the Pequod has reached the end of Bennett's process, but constructive marginalism can leave one a bit isolated. Milton Bennett characterizes the constructive marginal as one who is constantly creating his own reality (64). Indeed, Ahab, attaching a high importance to his own opinion, has constructed a reality, fed by his monomania, which perceives the whale, Moby-Dick, as a wall that, if torn down or, killed, will then reveal some hidden truth. Ahab's common characterization as a transcendentalist gone mad is not all that different, in the end, than Ahab's characterization as a constructive marginal gone mad. As Janet Bennett points out, to the constructive marginal "ambiguity seems overwhelming" (117), and ambiguity and hidden truth heap Ahab.

Another theme that, at first, may seem disconnected with a discussion of cultural sensitivity theory is Melville's treatment of democracy. In contrast to crews on merchant-marine vessels, which Ishmael has experience on, the Pequod is "barbaric, heathenish, and motley" (133). If the Pequod represents the United States and all her cultural diversity, our population, as Melville sees it, appears in a rather dim light. Still, Ishmael narrates of the dignity in free democracy, praising the common man's potential, which is definitely ethnorelative. Ishmael clearly opposes a pessimistic view of folks when he says, "man, in the ideal, is so noble and so sparkling, such a grand and glowing creature, that over any ignominious blemish in him all of his fellows should run to throw their costliest robes." A sentence later, he adds that the "dignity I treat of, is not the dignity of kings and robes, but that abounding dignity which has no robed investiture. Thou shalt see it shining in the arm that wields a pick or drives a spike; that democratic dignity" that Ishmael further characterizes as "centre and circumference of all democracy" (126). The sense of acceptance that resonates in these lines connects with cultural sensitivity theory. By openly embracing all the cultural difference on board the Pequod, Ishmael not only promotes democracy. He promotes notions that differences are necessary and preferable, that choices are not based on absolutes (M. Bennett 47-8).

At sea, Melville's' characterization of Ishmael still remains in a kind of transitional phase shifting between ethnocentrism and ethnorelativism. 
Ishmael's word choices can be denigrating, suggesting his sense of cultural superiority when he refers to the "diabolism" in Ahab's special crew, defensive diction that compounds with his characterization of Fedallah's "half-hissed" voice (236). Both examples illustrate Ishmael's sense of evil and the devil with those in question. This special crew has made its first appearance from below upon the first lowering for whales. The response to their appearance from Archy, the one who heard them earlier, helps put Ishmael's cultural sensitivity in perspective, for Archy seems to accept them. Stubb, too, seems to accept them; however, he does refer to the special crew members as "devils" (237). The rather existential Starbuck accepts Ahab's special crew but refers to their being onboard as "a sad business" (238). Ishmael also begins to accept these men, but his sensitivity will go beyond that of any of these other characters. Still, he wavers. Ishmael demonstrates some reversal when he elevates Daggoo above Flask, and his tendency towards minimization reoccurs with his line, "Verily, there is nothing new under the sun" (228), a rather insensitive remark since it posits that there is no cultural difference that Ishmael has not experienced, which is not exactly the most sensitive line coming from one who is to be the heroic constructive marginal at the end of the narrative. Yet, to Ishmael's credit, his weaving with Queequeg, at least symbolically, not only addresses time, but their collaborative effort points to integration.

Chapter 49, called The Hyena, may serve as a turning point for Ishmael as, at this point, much more of Melville's detailing going toward characterization of his narrator includes action that suits ethnorelativism a bit more. Here, Ishmael hints at traumatic experiences as a teacher of acceptance and adaptation. $\mathrm{He}$ mentions how life naturally throws these experiences into one's path and how he, particularly, has come to terms with these. For Ishmael, he now realizes that "nothing dispirits, and nothing seems worth disputing. He bolts down all events, all creeds, and beliefs, and persuasions" (247). His openness, his willingness to accept and adapt, will become intensified on the Pequod, noting that there's "nothing like the perils of whaling to breed this free and easy sort of genial, desperado philosophy" (247). Milton Bennett would recognize Ishmael's philosophy as one leading him toward constructive marginalism. Ishmael is accepting the world outside himself, and Melville's detailing begins to accelerate that notion at this stage in the novel. To be sure, Melville has picked a setting and cast of characters conducive to ethnorelative sentiments because sailors tend to have a range of experience that goes beyond most landlubbers. In chapter 53 The Gam, Melville clearly asserts this notion about sailors, attributed to shared profession and "common pursuit and mutually shared privations and perils" (261), all of which makes Ishmael becoming a constructive marginal aboard the Pequod rather moot unless evidence of 
ethnocentrism is seen onboard.

Fortunately, the very next chapter, The Town-Ho's Story, helps keep such a conflict front and center in the narrative. Although, Melville takes Ishmael off the ship and to another time to accomplish this. In Lima, Ishmael integrates, but the Peruvians' self-deprecating humor, their anti-Christian comments, and their tendency to minimalize with lines like "The world's one Lima" (274), all help bring out the ethnocentric side of Ishmael. Upon moving his detailing back aboard the Pequod, Melville brings Ishmael back to more ethnocentric characterizations. He has Ishmael acting metaphorically defensive when he equates hemp rope with "a dusky, dark fellow, a sort of Indian; but Manilla [rope] is as a golden-haired Circassian to behold" (303). And, he shows reversal when he raises a famished Fejee cannibal above the "unlighted gourmand, who nailest geese to the ground and fastest on their bloated livers in thy pate-defois-gras" (327). And, yes, even his tone echoes reversal.

Melville perhaps best presents insensitivity on board the Pequod when he turns to more commercial or capitalistic detailing. Ishmael feels for the whale. Whales, like buffalo, seen abstractly as humans, suggest a certain level of denial, the first level of ethnocentrism, through the actual hunting of them. Stubb evinces just such ethnocentric capitalism during the Pip episode. He "indirectly hinted, that though man loves his fellow, yet man is a moneymaking animal, which propensity too often interferes with his benevolence" (452). Stubb also has some strong words for the French. But, more to the case is the fast-fish/loose-fish analogy, which is not from Ishmael's mind but something that he reports on, and it strongly suggests sexism and nationalism. It is safe to say that Ishmael encounters plenty of ethnocentric behavior aboard the Pequod. From the ethnocentricity of Peleg, whom Ishmael encounters as he and Queequeg sign-up for their voyage; to both Peleg and Bildad being insensitive to Queequeg, especially Bildad, who tries to convert Queequeg; to the fight aboard ship in chapter 40, a fight that starts because of the cultural insensitivity of a Spanish sailor who equates a recent burst of lightening with Daggoo's teeth; to various crew members characterizing Ahab's special crew in culturally insensitive terms; to the men who listen to Ishmael's recounting of the Town-Ho's story at the Golden Inn in Lima; to the gross and insensitive capitalism that runs through the narrative in the hunting of the whales, Ishmael encounters ethnocentric behavior.

And, from his defensive start with Queequeg, Ishmael manages to rise above his ethnocentrism and grow considerably in cultural sensitivity. Early in their relationship, Ishmael denigrates Queequeg and feels superior to him most of the time, but in time he begins to see ways in which Queequeg is superior. Even before these feelings, Ishmael minimizes Queequeg, showing 
that Ishmael's process closely follows Bennett's DMIS. Before long, Ishmael is using Queequeg's harpoon as a razor and accepting the harpooner's smoking in bed. In addition to sleeping together in the same bed, clear integration occurs in the highly symbolic Monkey-rope scene, linking the two as if by the life force of an umbilical cord. They are that attached, integrated. So that, in the end, Ishmael is, indeed, a constructive marginal. One of the first signs that Ishmael was moving toward constructive marginalism was in chapter 61 Biographical. Ishmael's combination of accepting Queequeg while at the same time being defensive about him points to two sides at work in Ishmael, working simultaneously, indicative of the balance characteristic of constructive marginalism. In his essay on "Trainer Competencies" in Education for the Intercultural Student, Paige characterizes a good trainer with qualities such as openness, flexibility, tolerance of ambiguity, and sense of humor, to name a few (190-1). These are characteristics that Ishmael has. In his other essay in that book, Paige describes similar characteristics in the context of constructive marginality, calling the state an empowered one (16). As this potential trainer, as this constructive marginal, Ishmael is the only survivor of the Pequod. In the introductory essay to his book, Cushner presents cultural sensitivity theory that explains how Ishmael survives, for he states that those who have "a strong preference for interactions with similar others and an active avoidance of intercultural interactions will not fare well in 'a world' in which intercultural interactions are increasingly commonplace” (5). This is not to say that others aboard the Pequod are not culturally sensitive, for there are, namely Ahab and Queequeg; however, Ishmael is different in several ways, especially in his ability to adapt and integrate with a plurality of views.

Cultural sensitivity theory also connects with formal analyses of MobyDick in viewing Melville's theme of ambiguity. Ishmael realizes and accepts ambiguity. Wurzel writes, "Multiculturalism is the opposite of dogmatism, for it teaches us to accept the inevitable contradictions embedded in everything we learn" (5). Consider Ahab's monomania in opposition to Ishmael's cultural sensitivity. Ishmael is able to take in multiple points of view, and from the variety create his own reality. This is almost exactly how the Bennetts explain constructive marginalism. Milton Bennett, the designer of the DMIS, defines a constructive marginal as one who is constantly creating his own reality (64), and Janet Bennett adds, the "constructive marginal is a person who is able to construct context intentionally and consciously for the purpose of creating his or her own identity" (113). 


\section{Practical Applications of this Analysis}

Ishmael might be a natural, though, which is why reading, discussing, and writing about Melville's Moby-Dick would be helpful activities for those about to go abroad, and for those who cannot travel to experience different cultures, the novel, and Ishmael's characterization particularly, would, at least, expose them to the necessity of cultural sensitivity. Ashwill writes, "there are ways of developing intercultural competence that do not necessarily include language learning and education abroad" (21). Definitely, studying Melville's masterpiece can be one of those ways. Ishmael would most likely appeal to Ashwill as a trainer, for he emphasizes that good education in cultural sensitivity ought to stress the importance of interpersonal and relational skills and ambiguity tolerance and adaptivity, going as far as adding that such traits may very well characterize a modern leader. Think Barack Obama, and we may want study of Ishmael in Political Science. For now, though, study abroad seems like the logical place to start. The lessons of cultural sensitivity may not be limited to cultures. However, for our focus, consider what some of the top scholars in the field say is important about cultural sensitivity training, keeping in mind that following Melville's characterization of Ishmael may very well be revealing the ideal trainer. To be sure, intercultural sensitivity helps lead to intercultural competence (Hammer, Bennett, and Wiseman 422), and Ishmael's competence is again best seen in his ability to combine disparate ways of thinking. Anderson et al. ask, "are there activities that students should participate in prior to participation in a study abroad program that would significantly enrich their overseas experience and lead to greater intercultural sensitivity?" (46-7). Yes, a literature class designed with an eye toward cultural sensitivity would be both efficient and effective. In the Realistic Era that Melville presages, one could consider Sarah Orne Jewett's The Country of the Pointed Firs, a novel about acceptance, adaptation, and integration. In the present, Campbell McGrath's "City in the Clouds" in his Florida Poems can help show those other ways cultural sensitivity theory and, particularly Milton Bennett's DMIS, can be used in a context of environmentalism and ecocriticism, something that Melville address through his anti-capitalistic theme in connection with whale hunting. Cushner is correct when he writes, "only through significant and long-term experiences with people different from oneself can one become effective at living and working across cultures" (362). For those who need a crash course on the subject, I have a suggestion.

\section{Works Cited}

Anderson, Philip H., et al. "Short Term Study Abroad and Intercultural Sensitivity: A Pilot Study.” International Journal of Intercultural 
Relations. 30 (2006). 457-69.

Ashwill, Mark A. "Developing Intercultural Competence for the Masses."

International Educator. 13.2 (Spring 2004). 16-25.

Bennett, Janet M. "Cultural Marginality: Identity Issues in Intercultural

Training." Education for the Intercultural Experience. Ed. R. Michael

Paige. Yarmouth, ME: Intercultural, 1993. 109-135.

Bennett, Milton J. "Towards Ethnorelativism: A Developmental Model of

Intercultural Sensitivity." Education for the Intercultural Experience. Ed.

R. Michael Paige. Yarmouth, ME: Intercultural Press, 1993. 21-71.

Brown, Merlin. The Long Encounter: Self and Experience in the Writings of

Herman Melville. Chicago: U of Chicago P, 1960.

Bryant, John. "Democracy, Being, and the Art of Becoming America."

College English 59.6 (Oct. 1997), 705-711.

Chase, Richard. The American Novel and Its Tradition. Garden City: NY:

Doubleday, 1957.

Clinton, Bill. "One America in the $21^{\text {st }}$ Century." 1997 Commencement

Speech at the University of San Diego. In One America in the $21^{\text {st }}$

Century: the Report of President Bill Clinton's Initiative on Race. Steven F.

Lawson and John Franklin Hope. New Haven: Yale UP, 2009. A3-A7.

Cushner, Kenneth. "Intercultural Education from an International

Perspective: An Introduction." International Perspectives on Intercultural

Education. Ed. Kenneth Cushner. Mahweh, NJ: Erlbaum, 1998. 1-13.

Cushner, Kenneth. "Intercultural Education from an International

Perspective: Commonalities and Future Prospects." International

Perspectives on Intercultural Education. Ed. Kenneth

Cushner. Mahweh, NJ: Erlbaum, 1998. 353-370.

Dumm, Thomas L. "Who is Ishmael?" Massachusetts Review 46.3 (Sept.

2005), 398-414.

Egan, Philp J. "Time and Ishmael's Character in 'The Town-Ho's Story' of

Moby-Dick." Studies in the Novel 14.4 (Winter 82), 337-347.

Fiedler, Leslie A. Love and Death in the American Novel. New York: Criterion, 1960.

Hammer, Mitchell R., Milton J. Bennett, and Richard Wiseman. "Measuring Intercultural Sensitivity: The Intercultural Development Inventory."

International Journal of International Relations. 27 (2003). 421-43.

Hirsch, David H. "Notes: Melville’s Ishmaelite." AN\&Q 5.8 (Apr. 67), 115116.

Kalter, Susan. "A Student of Savage Thought: The Ecological Ethic in MobyDick and Its Grounding in Native American Ideologies." ESQ: A Journal of the American Renaissance 48.1-2 (2002): 1-40. 
Knutson, Susan Lyne. "Bowering and Melville on Benjamin's Wharf” A Look at Indigenous-English Communication Strategies." Essays on Canadian Writing 38 (Summer 89), 67-80.

Marx, Leo. The Machine in the Garden: Technology and the Pastoral Ideal in America. London: Free Association, 1991.

Matthiessen, F. O. Art and Expression in the Age of Emerson and Whitman. London: Oxford University Press, 1941.

Melville, Herman. Moby-Dick, or The Whale. New York: Penguin, 2001. Paige, R. Michael. "On the Nature of Intercultural Experiences and Intercultural Education.” Education for the Intercultural Experience. Ed. R. Michael Paige. Yarmouth, ME: Intercultural, 1993. 1-19.

Paige, R. Michael. "Trainer Competencies for International and Intercultural Programs." Education for the Intercultural Experience. Ed. R. Michael Paige. Yarmouth, ME: Intercultural Press, 1993. 167-99.

Paige, R. Michael, et al. "Assessing Intercultural Sensitivity: An Empirical Analysis of the Hammer and Bennett Intercultural Development Inventory." International Journal of Intercultural Relations. 27 (2003), 467-486.

Paterson, Mark E. "Democratic Leadership and Narrative Authority in MobyDick." Studies in the Novel 16.3 (Fall 84), 288-303.

Schultz, Elizabeth. "Melville's Environmental Vision in Moby-Dick." Interdisciplinary Studies in Literature and Environment 7.1: 2000, 97113.

Wurzel, Jaime S. "Multiculturalism and Multicultural Education." Toward Multiculturalism: A Reader in Multicultural Education. Ed. Jaime S. Wurzel. Yarmouth, ME: Intercultural Press, 1988. 1-13.

Zoellner, Robert. The Salt-Sea Mastodon: A Reading of Moby-Dick. Berkeley: University of California Press, 1973. 